\title{
CALENDAR OF LASER CONGRESSES
}

\section{7}

\section{American Society for Laser Medicine and Surgery (ASLMS)}

Date: $4 / 11$ to $15 / 2007$

Cite: Grapevine, Texas, USA

Congress Chairman: Kristen M. Kelly

President: A. Jay Burns

Secretary: J. Stuart Nelson

Web address: http://www.aslms.org/

Message from association:

We Are Only Two Months Away From The Annual Conference In Grapevine, Texas! Kristen M. Kelly, M.D.

As I highlighted in previous Newsletter columns, we are excited to introduce a new course entitled, "How Can We Use Diagnostic Information". This course will be a forum for clinicians, scientists, engineers and industry representatives to discuss the information content afforded by optical diagnostics as well as application and optimization of these technologies. There will be ample opportunity for discussion and interaction during this course, which will be offered free to residents and fellows in training. (to be continued to website)

\section{British Medical Laser Association (BMLA) \\ Date: $6 / 7$ to $8 / 2007$ \\ Cite: Liverpool, UK \\ Congress Chairman: Caroline Sudworth \\ President: Harry Moseleys \\ Secretary: Caroline Sudworth \\ Web address: http://www.bmla.co.uk/ \\ Message from association:}

2007 Annual Meeting and AGM, Museum of Science and Industry in Manchester 7th and 8th June 2007

We are pleased to announce the first details of the BMLA Annual Meeting and AGM to be held in June 2007 in Manchester, UK. This is an ideal opportunity to meet with others working in your field, to broaden your knowledge and undertake training. This year we are continuing to offer training courses in combination with parallel conference sessions. (to be continued to website)

\section{Japan Photodynamic Association (JPA)}

Date: 6/16 to17/2007
Cite: Tochigi, Japan

Congress Chairman: Tetsuya Nakamura

President: Harubumi Kato

Web address: http://square.umin.ac.jp/jpa/

Message from association:

The Japan Photodynamic Association (JPA) started as Japan Chapter of The International Photodynamic Association. The first congress is hosted by Prof Yoshihiro Souda, Tokyo Medical University.

This 17th Congress theme is "Diagnosis and treatment in Light Century".

(to be continued to website)

\section{Japan Laser Therapy Association (JaLTA)}

Date: $6 / 30$ to $7 / 1 / 2007$

Cite: Tokyo, Japan

Congress Chairman: Kazuhiro Mizutani

Secretary General: Masahito Kawatani

Web address: http://square.umin.ac.jp/jalta/

Message from association:

Theme is "EBM and future of Laser Treatment".

(to be continued to website)

\author{
Japanese Association for Nd:YAG Laser \\ Dentists (JANLD) \\ Date: $7 / 21$ to $22 / 2007$ \\ Cite: Kobe, Japan \\ Congress Chairman: Takahide Komori \\ President: Koukichi Matsumoto \\ Secretary General: Toshihide Noguchi, Takehito Nanri
}

\section{Japan Association for $\mathrm{CO} 2$ Laser Dentists (JACLD)}

Date: $7 / 21$ to $22 / 2007$

Cite: Kobe, Japan

Congress Chairman: Takahide Komori

President: Koukichi Matsumoto

Secretary General: Yoshio Kato, Masahiro Hirata

\section{Japan Society for Laser Surgery and Medicine (JSLSM)}

Date: $9 / 14$ to $15 / 2007$

Cite: Asahikawa, Japan

Congress Chairman: Shinichi Kasai

President: Harubumi Kato

Web address: http://www.jslsm.com/

Message from association:

This 28th Congress theme is "Challenge for state-of- 


\section{CALENDAR OF LASER CONGRESSES}

the-art medical treatment of light". We hope fruitful discussion on the present medical laser should be carried out. There will provide safety education seminar to aim expanding laser medical specialist.

(to be continued to website)

\section{European Medical Laser Association (EMLA)}

Date: $11 / 20$ to $22 / 2007$

Cite: Prague 1, Czech Republic

Web address: http://www.laser-prague-2007.cz/

Message from association:

Laser Prague 2007

(11TH INTERNATIONAL JOINT EMLA AND WALT LASER CONGRESS)

Main Topic: Convergency of surgical and therapeutic lasers - future or present issue?

(to be continued to website)

\section{Japanese Association for Laser and Sports Medicine (JALSM) \\ Date: 10/2007 (No definite dates yet) \\ Cite: Nagano, Japan \\ Congress Chairman: Yoshimi Asagai}

\section{International Society for Laser Surgery \& Medicine (ISLSM)}

Date: $11 / 8$ to10/2007

Cite: Firenze, Italy

Congress Chairman: Leonald Longo

President: Harubumi Kato

Secretary General: Abraham M. Baruchin

Web

http://www.laserflorence.org/yearsMeeting.htm

\section{Laser Florence}

Date: $11 / 8$ to10/2007

Cite: Firenze, Italy

President: Leonald Longo

Web address: http://www.laserflorence.org/about.htm

Message from association:

The Renaissance of Art, Science \& Friendship

Leonardo Longo

The series of courses and Laser Florence congresses started in 1997 with three objectives:

- to increase the number of physicians, engineers and scientists who correctly use lasers in medicine, surgery and human sciences

- to facilitate the exchange of theoretical and practical experiences between different world wide schools of human sciences and medicine through discussion and demonstration

- to foster contacts between industry, engineering, physics, medicine and surgery. (to be continued to website)

\section{Antoni De Gimbernat Foundation}

Date: $11 / 9$ to11/2007

Cite: Cambrils(Tarragona), Spain

Chairman: Mario Trelles

Web address: http://laser-spain.com/FAG/en/

Message from association:

\section{ANTONI DE GIMBERNAT FOUNDATION \\ GRANT 2007 \\ Mario Trelles}

This year's course in Vilafortuny on the subject of "Aesthetics, Dermatology, Vascular and Incisional Surgery with Lasers"

The ANTONI DE GIMBER-NAT FOUNDATION, located at the Instituto Médico Vilafortuny (Cambrils, Spain), was founded in 1990 with the board of trustees integrated by the several Governmental Institutions such as the Town Hall of Cambrils, the County Council of Tarragona, The Medical Sciences Academy of Tarragona, and the Department of Morphologic Sciences (Medical Faculty of the University of Valencia) in Spain, with the main aim of carrying out work of social interest, to improve health and the quality of life through research

(to be continued to website)

\section{8}

\section{International Association of Dental Traumatology (IADT)}

Date: $1 / 12$ to $14 / 2008$

Cite: Nagoya, Japan

Congress Chairman: Mitsuhiro Tsukiboshi

President: Marie Therese Flores

Secretary General: Mitsuhiro Tsukiboshi

Web address: http://www.iadt-dentaltrauma.org/web/

Message from association:

XV World Congress on Dental Traumatology January 12-14, 2008

Mitsuhiro Tsukiboshi, Program Chairman and President-Elect

It is my privilege, on behalf of International Association of Dental Traumatology, to invite you to the 15th World Congress on Dental Traumatology in Nagoya

Nagoya is the third largest city in Japan. It takes 2 hours to travel by bullet train from Tokyo and $35 \mathrm{~min}$ utes from Kyoto, the world famous historical place. Among the best sight-seeing places in Nagoya is Tokugawa Art Museum with its outstanding history of Shogun. Mt. Fuji which you can see in the picture 


\section{CALENDAR OF LASER CONGRESSES}

above, is located nearby. (to be continued to website)

\section{World Association for Laser Therapy \\ (WALT)}

Date: Will soon be announced on the web site.

Cite: Sun city, South Africa

Congress Chairman: Heidi Abrahamse

President: Farouk al-Watban

Secretary General: Tony Pinheiro

Web address: http://www.walt.nu/

Message from association:

South Africa Will Host WALT 2008

The Executive Council has chosen South Africa as the venue for WALT 2008. The Laser Research Group in the Faculty of Health Sciences at the University of Johannesburg focuses on Phototherapy using low powered lasers for the treatment of medical conditions including cancer and wound healing.

(to be continued to website)

\section{International Society for Lasers in Dentistry (ISLD)}

Date: $7 / 26$ to $28 / 2008$

Cite: Hong Kong

Congress Chairman: Jonny Wong

President: Samir Namour

Secretary General: Aldo Brugnera 